LEDA CAMILA PESSOA DE MELLO CARTAXO ASSUNÇÃO

\title{
O FEDERALISMO FISCAL NO ORDENAMENTO JURÍDICO BRASILEIRO: Uma Análise Sistêmica
}

\author{
Dissertação de Mestrado \\ Orientador: Professor Titular Dr. Heleno Taveira Torres
}

UNIVERSIDADE DE SÃO PAULO

FACULDADE DE DIREITO

São Paulo - SP

2017 


\section{O FEDERALISMO FISCAL NO ORDENAMENTO JURÍDICO BRASILEIRO: Uma Análise Sistêmica}

Dissertação apresentada à Banca Examinadora do Programa de Pós-Graduação em Direito, da Faculdade de Direito da Universidade de São Paulo, como exigência parcial para obtenção do título de Mestre em Direito, na área de concentração Direito Econômico, Financeiro e Tributário, sob a orientação do Professor Titular Dr. Heleno Taveira Torres.

UNIVERSIDADE DE SÃO PAULO

FACULDADE DE DIREITO

São Paulo - SP 
O FEDERALISMO FISCAL NO ORDENAMENTO JURÍDICO

BRASILEIRO: Uma Análise Sistêmica

Dissertação apresentada à Banca Examinadora do Programa de Pós-Graduação em Direito da Universidade de São Paulo, como exigência parcial para obtenção do título de Mestre em Direito, na área de concentração de Direito Econômico, Financeiro e Tributário, sob a orientação do Professor Titular Dr. Heleno Taveira Torres.

Orientador:

Professor Titular Dr. Heleno Taveira Torres

UNIVERSIDADE DE SÃO PAULO

FACULDADE DE DIREITO

São Paulo - SP 


\section{Catalogação da Publicação \\ Serviço de Biblioteca e Documentação}

Faculdade de Direito da Universidade de São Paulo

Cartaxo, Leda.

O FEDERALISMO FISCAL NO ORDENAMENTO JURÍDICO BRASILEIRO: Uma Análise Sistêmica / Leda Camila Pessoa de Mello Cartaxo Assunção ; Orientador Professor Titular Doutor Heleno Taveira Torres - São Paulo, 2017.

$122 \mathrm{p}$.

Dissertação (Mestrado - Programa de Pós-Graduação em Direito Econômico, Financeiro e Tributário) Faculdade de Direito, Universidade de São Paulo, 2017.

1. Federalismo. 2. Sistema Tributário Nacional. 3. Repartição de Competências Tributárias. 4. Redução das Desigualdades Regionais. 5. Desenvolvimento. I. Torres, Heleno Taveira, orient. II. Título. 
Dedico este trabalho a meus pais, Otacílio e Fátima, sempre fontes de orgulho e inspiração. 
O poder nunca é propriedade de um indivíduo; pertence a um grupo e existe somente enquanto o grupo se conserva unido.

Hannah Arendt 


\section{AGRADECIMENTOS}

Devo agradecimento profundo ao meu orientador, Professor Heleno Torres, que me guiou pelos caminhos da pesquisa acadêmica, invariavelmente me auxiliando com seus conhecimentos e ideias inovadoras sobre a solidificação e amadurecimento do federalismo fiscal brasileiro, com a alegria da transmissão do conhecimento inerente àqueles que têm amor ao magistério.

Agradeço, ainda, à Faculdade de Direito da Universidade de São Paulo, que merece o reconhecimento que tem nacional e internacionalmente, sendo um local de respeito ao estudo do Direito e que fomenta de maneira fundamental o debate sobre temas centrais para o desenvolvimento do Brasil.

Igualmente, agradeço a todos os meus professores e colegas durante esse período de aprendizado, pelas aulas, pelo conhecimento, pelas amizades e pela oportunidade de debater os rumos da pesquisa e encontrar caminhos para a finalização desse trabalho.

Agradeço profundamente aos meus pais, Otacílio e Fátima Cartaxo, por todo o incentivo e amor ao longo de toda a minha vida, e ao meu marido, Gustavo Assunção, pelo companheirismo e apoio incondicional. 


\section{RESUMO}

CARTAXO, Leda. O FEDERALISMO FISCAL NO ORDENAMENTO JURÍDICO BRASILEIRO: Uma Análise Sistêmica. 2017. 122 p. Dissertação (mestrado) Faculdade de Direito, Universidade de São Paulo, São Paulo, 2017.

A presente dissertação analisa o sistema tributário brasileiro, em seu bojo constitucional, sob a perspectiva da repartição de competências. Dessa feita, aborda-se a questão do federalismo vertical e horizontal, do ponto de vista sistêmico, com base na teoria de Niklas Luhmann, entendendo as atribuições de cada poder do Estado na Federação, sempre no sentido de permitir a estabilização das expectativas normativas constitucionais.

No contexto nacional, trata-se a questão da chamada guerra fiscal entre os Estadosmembros, bem como o papel do Conselho Nacional de Política Fazendária (CONFAZ) e do Senado Federal. No atual cenário econômico e social interno, resta evidente a imprescindibilidade da revisão de alguns aspectos estruturais do nosso federalismo fiscal. A atual conjuntura da competição fiscal horizontal, bem como os elementos embasadores do Imposto sobre operações relativas à Circulação de Mercadorias e sobre prestações de Serviços de transporte interestadual, intermunicipal e de comunicação (ICMS) geram um ambiente de insegurança jurídica para os jurisdicionados, fomentando um baixo índice de transparência e eficiência reduzida, trazendo prejuízos econômicos para os entes federados e para a Federação como um todo. Busca-se, portanto, identificar quais as deficiências do sistema tributário nacional e quais os instrumentos possíveis para promover um maior equilíbrio entre os Estados, favorecendo a cooperação intergovernamental, a adoção de políticas de desenvolvimento e de redução das desigualdades regionais, trazendo ao federalismo fiscal brasileiro maior equilíbrio em sua horizontalidade e verticalidade. Dessa forma, da análise do sistema de direito brasileiro, notadamente do sistema tributário nacional, verifica-se que o fortalecimento do federalismo horizontal, bem como uma maior atuação por parte do Senado Federal, utilizando-se de suas prerrogativas como instituição responsável pela agregação das unidades federativas e propulsora de redução das desigualdades regionais, permitiria de forma mais efetiva a concretização dos princípios e objetivos constitucionais.

Palavras-chave: Sistema Tributário Nacional; Repartição Constitucional de Competências; Federalismo Fiscal; Guerra Fiscal; Senado Federal 


\begin{abstract}
CARTAXO, Leda. FISCAL FEDERALISM IN BRAZILIAN LAW: A Systems Analysis. 2017. 122 p. Master thesis - Faculdade de Direito, Universidade de São Paulo, São Paulo, 2017.
\end{abstract}

This dissertation analyzes the Brazilian tax system, by the constitutional view, from the perspective of division of powers. It deals with the issue of vertical and horizontal federalism, from the systemic point of view, based on the theory of Niklas Luhmann, understanding the attributions of each state power in the Federation, always in the sense of allowing the stabilization of normative constitutional expectations.

In the national context, the question of the so-called fiscal war between the states, and the role of the National Council for Financial Policy (CONFAZ) and the Federal Senate. In the current economic and internal social context, the revision of some structural aspects of our fiscal federalism remains indispensable. The current situation of the horizontal fiscal federalism and the funding elements of the tax on transactions regarding the circulation of goods and on interstate transport services benefits, intercity and communication (ICMS) generate legal uncertainty environment, fostering a context with low level of transparency and reduced efficiency, bringing economic losses to the federal Union and to the Federation as a unity. The objective is, therefore, to identify the shortcomings of the national tax system and which are the possible instruments to promote a better balance between states, encouraging intergovernmental cooperation, the adoption of development policies and reducing regional inequalities, bringing the fiscal federalism Brazilian greater balance in its horizontality. Thus, by the Brazilian legal system analysis, notably the national tax system, it seems that the strengthening of horizontal federalism and a greater action by the Federal Senate, using its prerogatives as an institution responsible for aggregation federative units and reducing the regional inequalities, would allow a more effectively implementation of the constitutional principles.

Keywords: National Tax System; Constitutional Division of Responsibilities; Fiscal Federalism; Tax war; Federal Senate 


\section{SUMÁRIO}

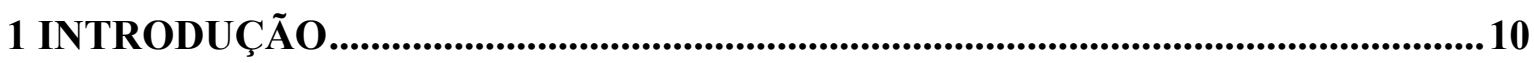

2 FORMAS DE ORGANIZAÇÃO DE ESTADO...........................................................13

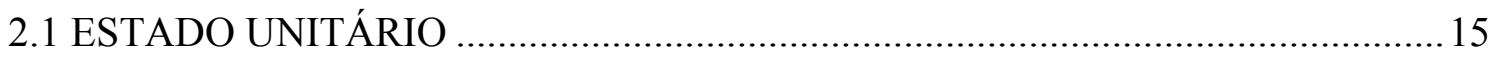

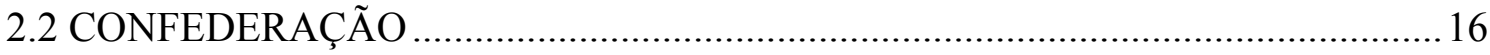

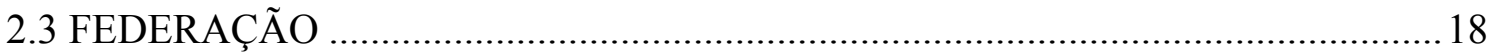

2.3.1 Espécies de Federalismo ...................................................................................22

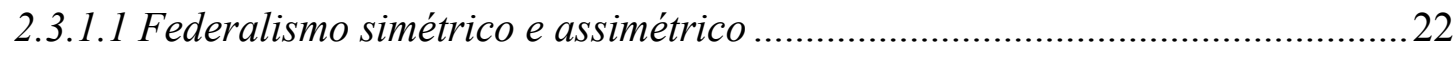

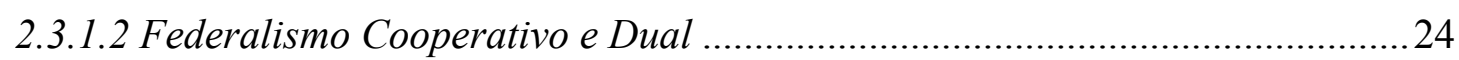

2.3.1.3 Federalismo por Agregação e por Desagregação .............................................25

3 SISTEMA E DIREITO ...........................................................................................27

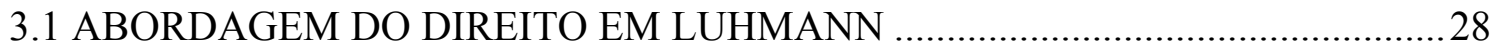

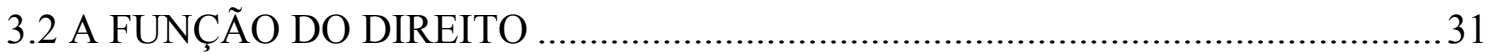

40 ESTADO FEDERAL BRASILEIRO.......................................................................35

4.1 PERSPECTIVA HISTÓRICA DO FEDERALISMO NO BRASIL ...........................35

4.2 A INDISSOLUBILIDADE DA REPÚBLICA FEDERATIVA DO BRASIL ..........42

4.2 O FEDERALISMO FISCAL NO BRASIL ............................................................

4.2.1 Bases do Federalismo Cooperativo ………………...............................................47

50 SISTEMA TRIBUTÁRIO......................................................................................52

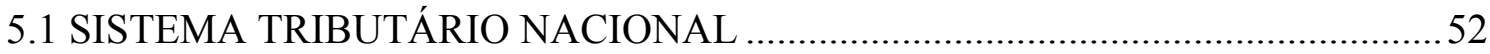

5.2. REPARTIÇÃO CONSTITUCIONAL DE COMPETÊNCIAS …………………......55

5.2.1 Imposto sobre o Consumo no Brasil ....................................................................58

5.3 PRINCÍPIOS CONSTITUCIONAIS TRIBUTÁRIOS E LIMITAÇÕES AO

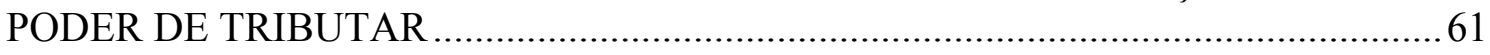

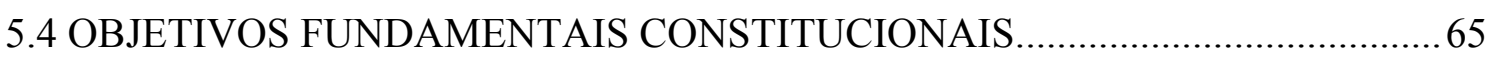

6 ANÁLISE SISTÊMICA DO FEDERALISMO FISCAL BRASILEIRO.....................70

6.1 IMPACTOS DO FEDERALISMO FISCAL NOS ESTADOS-MEMBROS ............70

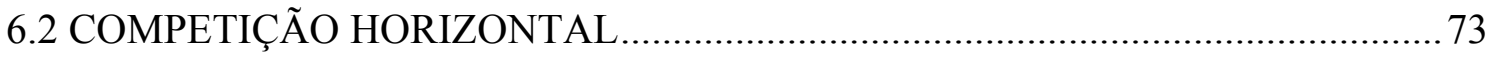

6.1.1 O papel do CONFAZ .........................................................................................77

6.1.2 O Senado Federal como agente de políticas públicas .......................................87

6.3 RELAÇÃO ENTRE O FEDERALISMO FISCAL E A SEGURANÇA JURÍDICA94

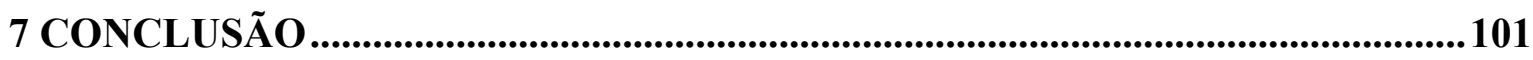

REFERÊNCIAS.........................................................................................................111 


\section{INTRODUÇÃ̃o}

Este estudo foi desenvolvido no intuito de analisar o federalismo fiscal brasileiro sob a perspectiva sistêmica, baseada na teoria de Niklas Luhmann, com o intuito de identificar quais as implementações e adequações são necessárias para um melhor funcionamento do Estado Federativo brasileiro.

Niklas Luhmann utiliza-se de uma visão sistêmica do direito, em que reconhece a complexidade da interação entre direito e sociedade, explicitando o teor autopoiético dessa interação, por meio de estruturas normativas que geram estabilidade ao sistema.

Inicialmente, cumpre-se destacar que a abordagem de Estado aqui realizada parte do conceito definido por Bobbio, o qual ensina que o conceito de Estado não é um conceito universal, mas descreve e define uma forma específica de ordenamento político surgida na Europa a partir do século XIII até os fins do século XVIII ou inícios do século XIX. Após esse período, esse conceito se espalhou por todo o mundo civilizado, apesar de ter sofrido alterações em suas condições originárias.

Partindo-se da trilogia, povo, governo e território, trazida por Jellinek como componentes do Estado, aborda-se a questão da soberania. O poder do Estado é soberano e não se pode conceber um Estado sem referida característica. A soberania é a essência que torna o poder do Estado supremo em seu ambiente interno e que, além de suas fronteiras, demonstra a igualdade e independência em relação aos Estados estrangeiros.

Quanto às formas de organização do Estado, sabe-se que o Brasil adotou o modelo de federalismo cooperativo. Quando se fala de Federação, essencial tratar da perspectiva do federalismo de Proudhon. O filósofo político baseia sua teoria federativa em um pacto ou contrato político, com o intuito de preservar e resguardar a identidade dos Estados que compõem a Federação, respeitando a liberdade individual de cada um deles.

Dessa feita, o federalismo proudhoniano se opõe ao processo centralizador, tendo em vista que busca preservar a autonomia dos seus membros. Referida visão tem um componente histórico, pois o pensamento federalista de Proudhon era uma tentativa de 
resposta ao movimento nacionalista ocorrido na Europa em busca de unidade, utilizando-se da liberdade e respeito dos territórios membros da Federação.

Busca-se, com foco no Poder Legislativo, compreender os ajustes necessários e principais deficiências existentes entre os entes federados, os quais dificultam a evolução do sistema tributário nacional, ocasionando a competição horizontal.

O sistema tributário nacional sofreu suas últimas reformas substanciais em 1967 e 1988 e, desde então, o contexto econômico e social interno se modificou, mostrando-se latente a necessidade de revisão de alguns aspectos estruturais acerca da configuração do federalismo cooperativo pátrio.

Atualmente, o federalismo horizontal, notadamente o imposto sobre o consumo estadual (Imposto sobre Circulação de Mercadorias e Serviços ou ICMS) em seu formato presente, favorece a competição fiscal entre os Estados-membros, a qual gera insegurança jurídica para os contribuintes e traz prejuízos econômicos.

Nesse contexto, surge a necessidade de se estudar a implantação de instrumentos que promovam um maior equilíbrio entre os Estados, favorecendo a cooperação intergovernamental com vistas à implementação de políticas de desenvolvimento e de redução das desigualdades regionais, possibilitando-se um ambiente com maior segurança jurídica.

Não se pode deixar de atentar para os ditames da Constituição Federal, em especial para o papel do Senado Federal, como ente representante dos Estados-membros, na promoção de medidas relativas à redução das desigualdades regionais, erradicação da pobreza e promoção do desenvolvimento, objetivos previstos no art. $3^{\circ}$ da Constituição Federal de 1988.

As inúmeras propostas legislativas que existem em trâmite no Congresso Nacional com o objetivo de promover uma reforma fiscal esbarram na dificuldade política de se conseguir alianças para um pacto federativo. A inexistência de políticas públicas que promovam o desenvolvimento nacional é latente, principalmente que busquem o desenvolvimento. 
Tendo em consideração esses importantes fundamentos, a Constituição não permite que seja abolido o federalismo cooperativo, característica da rigidez da Constituição material presente nos Estados que adotam a organização federativa. Trata-se de cláusula pétrea que define a identidade do Estado brasileiro, sendo vedada qualquer tentava de centralização, em detrimento da descentralização das competências legislativas ou que afronte a redução das desigualdades regionais ou a promoção do desenvolvimento equilibrado

No entanto, é a partir do desenvolvimento que teremos uma Federação unida e solidificada. Merece atenção, igualmente, o princípio da lealdade federativa, segundo o qual, os entes federados devem buscar condutas que visem a manter e fortalecer o pacto federativo, nos termos dos ditames constitucionais. Veja-se que, aliado aos objetivos da Federação, traçados no art. $3^{\circ}$ da Carta Magna, a União e os Estados-membros devem contribuir para o desenvolvimento, sem ferir a unidade federativa.

Por fim, o melhor funcionamento da organização federal é intimamente ligado ao espírito federativo, consubstanciado no sentimento de solidariedade nacional. Mesmo que seja sofisticada e democrática a estrutura de uma Federação, nunca funcionará de maneira adequada, enquanto não existir tolerância mútua entre os governos central e regionais, de forma vertical e horizontal, respeitando-se a partilha de competências determinada pela Constituição Federal.

Dessa feita, a justificativa maior para o estudo está na conscientização da importância do sistema tributário brasileiro como mecanismo de transformação social, desenvolvimento, redução das desigualdades regionais e efetivação dos ditames constitucionais. Isso porque, além da função de financiar as atividades estatais, a tributação tem seu mais nobre fundamento no conceito de agente social, no contexto sistêmico do Direito. 


\section{CONCLUSÃO}

Ao longo da análise tecida acerca do conceito de Estado, percebe-se que não há um conceito único, mas a concepção atual do termo se refere à forma de ordenamento político surgida na Europa a partir do século XIII até os fins do século XVIII ou inícios do século XIX, possuindo, portanto, seu fundamento na história europeia. Após esse período, estendeu-se a todo mundo civilizado, ainda que com aspectos diversos das condições originarias e concretas.

A ideia de Estado trazida por Kant menciona a existência de um pacto social, estabelecido pelo povo por meio do contrato original, consagrando-se a legitimidade de um Estado. Tendo em vista o contrato original, todos os indivíduos de um povo renunciam à sua liberdade externa para participar da sociedade como partes de uma coisa pública. Assume-se, assim, uma condição jurídica, vez que esta renúncia surge de sua própria vontade legisladora.

Sabe-se que o Estado possui três elementos constitutivos, quais sejam: povo, território e governo, sendo os dois primeiros prévios ao Estado. O elemento subjetivo abarca o conjunto de indivíduos que compartilham da mesma identidade cultural, em um território delimitado, onde se adquirem direitos e deveres. O segundo elemento, trata do critério físico de delimitação da competência. Já o governo tem sua configuração na junção dos órgãos públicos de um Estado.

No âmbito da organização dos Estados, foi analisado o modelo federativo, adotado pelo Brasil. Por Federação entende-se um tipo de organização de poder de Estado, segundo a qual há a repartição de poderes estatais em ao menos dois níveis verticais. Diferentemente das confederações, em que há a preservação da soberania dos Estadosmembros, na Federação, os Estados-membros apenas possuem representatividade perante o direito constitucional interno, sendo representados externamente apenas em conjunto, pela figura da União. 
Na perspectiva de Proudhon, o federalismo tem relação com um pacto ou contrato político, cujo objetivo é manter a identidade dos Estados que compõem a Federação, respeitando a liberdade individual de cada um deles. Dessa maneira, federalismo proudhoniano vai de encontro ao processo centralizador, pois visa a manter a autonomia dos seus membros. Dentro de um contexto histórico, o pensamento federalista de Proudhon era uma tentativa de resposta ao movimento nacionalista vivido na Europa e busca de unidade, utilizando-se da liberdade e respeito dos territórios membros da Federação.

A União Federal, por sua vez, assume a característica de coordenação dos entes federados, respeitando-se os interesses locais. Resta bastante evidente o aspecto de mutualidade entre os membros, sempre visando o bem comum da Federação. Os pilares da teoria Proudhoniana são a liberdade e a autoridade, a liberdade dos entes membros da Federação e a autoridade da União, com equilíbrio e harmonia.

A descentralização do poder promovida pelo pacto federativo se concretiza pela formulação de ordenamentos jurídicos igualmente descentralizados, diversamente da descentralização tão-somente administrativa presente nos Estados unitários descentralizados.

A repartição de competências existente nos Estados Federados permite a autonomia constitucional dos Estados-membros de forma relativa e não absoluta, visto que devem ser observados os limites constitucionalmente estabelecidos.

Um dos elementos mais importantes da Federação é o respeito à harmonia entre os entes federados, reforçando o espírito federativo e de solidariedade. Referida harmonia é estabelecida por meio da Constituição Federal, símbolo do pacto federativo, que tem o papel essencial de coordenar os entes da Federação.

Quando se fala em Federação, tem-se em mente sempre a organização e coordenação. A organização pode ser concebida como uma ordem sistemática. No entanto, sabe-se da dificuldade doutrinária em se conceituar a palavra sistema, sem que haja no mundo jurídico uma teoria uníssona acerca da matéria. 
Sob a ótica do professor Tércio Sampaio Ferraz Júnior, o direito não é um instituto que se pode facilmente conceituar lógica e racionalmente de maneira sistematizada. Já sob a perspectiva de Luhmann, compreendendo-se a sociedade como um sistema complexo, a interação entre direito e sociedade teria uma relação autopoiética, por meio de estruturas normativas que dão estabilidade ao sistema.

Luhmann destaca a complexidade das relações sociais, compreendida por intermédio do sistema autopoiético, no qual o direito não só trata da valoração comunicativa, mas da comunicação em todos os modos de comportamento que o direito abarca e normatiza.

A concepção da estabilização das expectativas normativas como função do direito é bastante evidente na teoria Luhmanniana, tendo em vista que o direito tem propensão à crise de confiança, que se transmite simbolicamente. Consequentemente, a função da norma é estabilizar-se.

Acerca do sistema de direito brasileiro, um dos seus fundamentos é a indissolubilidade da Federação Brasileira, a qual está prevista no art. $1^{\circ}$ da Constituição Federal de 1988, corroborando a autonomia dos Estados-membros.

Portanto, a Constituição não permite retrocesso quanto à opção pelo federalismo cooperativo, tratando-se de cláusula pétrea em nosso sistema constitucional, vedando-se qualquer medida que tenha por objetivo fazer prevalecer a unidade central em detrimento dos entes federados ou que obste a redução das desigualdades regionais ou a promoção do desenvolvimento equilibrado.

Portanto, o sistema federativo adotado em 1988 tem como pilar central a cooperação entre os entes federados, visando a expansão de políticas públicas que propiciem a descentralização entre as unidades do federalismo, permitindo a concretização dos objetivos constitucionais, em busca do desenvolvimento e redução das desigualdades regionais.

A Constituição Federal de 1988 privilegiou a descentralização e maior independência dos Estados e Municípios. Na alçada tributária, refletiu-se na ampliação das 
competências tributárias dos Estados e Municípios e no aumento das transferências de receitas federais.

Infelizmente, as mudanças promovidas no âmbito do federalismo fiscal pela Constituição de 1988 geraram o aumento das responsabilidades sociais criadas ou alargadas do governo federal, por meio da instituição de novos tributos visando o cumprimento dessas novas obrigações. Nesse sentido, o sistema tributário nacional teve seu equilíbrio e sua eficiência reduzidos. A proliferação das contribuições sociais traduziase na necessidade do cumprimento das novas obrigações da União e buscava evitar o repasse aos Estados e Municípios.

Dessa forma, o sistema fiscal brasileiro tem a difícil tarefa de buscar conciliar três objetivos principais. Primeiramente, a necessidade de uma arrecadação tributária que atenda aos gastos crescentes (especialmente o orçamento da seguridade social) e ao controle do déficit. Em segundo lugar, a permanência de uma autonomia em relação aos recursos provenientes do sistema de transferências. Por fim, viabilizar a distribuição regional dos recursos, visando-se a compensação decorrente da concentração econômica e conciliando os interesses das diversas unidades que compõem a federação.

Essa relação entre os membros da Federação, sejam União, Estados ou Municípios, deve pautar-se sempre pela segurança jurídica, eficiência, integração, redução das desigualdades regionais, de acordo com todos os fundamentos do Estado Democrático de Direito previsto na Constituição Federal de 1988.

Referida cooperação não deve agir apenas de forma vertical, partindo-se da União em direção aos Estados e, posteriormente, dos Estados em direção aos Municípios, mas deve operar também horizontalmente, no bojo da Constituição Federal, favorecendo o desenvolvimento e a redução das desigualdades regionais, sempre estando alerta para os objetivos constitucionais.

Na linha da realização concreta e da força normativa da Constituição, conforme ensina Konrad Hesse, esta tem o dever de estabelecer meios para que os objetivos da Federação sejam implementados, traduzindo-se em realidade. Especialmente no caso das Federações, em respeito ao Princípio da Lealdade Federativa, os compromissos de 
cooperação e solidariedade são essenciais, permitindo-se as ações e políticas públicas necessárias para a consecução dos objetivos em favor da unidade.

Portanto, os objetivos constitucionais devem ser percebidos como guias para a atuação do Estado, servindo como diretrizes vinculantes, em todas as relações do pacto federativo. A obtenção de uma sociedade livre, justa e solidária somente é viável quando se permite o desenvolvimento nacional por meio da redução das desigualdades regionais e erradicação da pobreza.

Nesse sentido, com fundamento na teoria Luhamanniana, a Constituição assume a forma de acoplamento estrutural, permitindo a influência recíproca e contínua entre direito e política, em que a atividade legislativa e a aplicação concreta do Direito Constitucional relacionam a validade e a sentido.

O desenvolvimento, em seu contexto mais atual, está relacionado com avanço econômico e social, tanto nacional quanto regional. Os entes federados devem agir como membros de um mesmo quebra-cabeça, pois são responsáveis por fazer o todo ser formar solidariamente.

Para que haja a interação e a solidariedade desejadas, resta necessária a consciência da diversidade política, cultural, social e econômica vivenciada no Brasil, atentando-se ao Princípio da Lealdade Federativa e visando uma sociedade livre, justa e solidária, com o objetivo central de implantar as melhores políticas pública. Dessa forma, eficiência e crescimento devem caminhar juntos, em busca do desenvolvimento do Brasil como um todo, como Federação.

Nesse sentido, o processo de descentralização fiscal, com a observância dos princípios que guiam o federalismo, pode ser um mecanismo de colaboração para a gestão eficiente do gasto público, visto que, em diversos setores, somente o ente que está mais perto da sociedade pode entender e escolher as melhores políticas públicas, favorecendo o desenvolvimento, reduzindo os custos operacionais, bem como estimulando os investimentos públicos e privados na economia. 
A competição horizontal vislumbrada no Brasil, por meio da chamada guerra fiscal entre os Estados-membros, vem sendo discutida há bastante tempo. Os incentivos fiscais vêm sendo concedidos sem a autorização unânime do CONFAZ, em afronta clara às normas legais e constitucionais vigentes.

Nessa esteira, muitos dos incentivos fiscais concedidos ilegalmente já foram declarados inconstitucionais pelo Supremo Tribunal Federal, acertadamente. No entanto, faltam normas inibidoras da referida prática, com aplicação de sanções mais rigorosas. Alternativamente, seria viável a edição de uma Lei Complementar que permita a concessão de benefícios fiscais sem a concordância unânime dos membros do CONFAZ.

Com a Lei Complementar $n^{\circ}$ 24/75 (artigo 34, parágrafo 8 , ADCT), foi concedida ao CONFAZ a harmonização do sistema, no intuito de evitar a competição físcal horizontal, a qual foi incorporada à legislação democrática, por meio do Ato das Disposições Constitucionais Transitórias (ADCT).

A Lei Complementar no 24/75 condiciona a concessão de benefícios fiscais no âmbito do ICMS à unanimidade das deliberações do CONFAZ. No entanto, não parece razoável a obrigatoriedade de uma decisão unânime para fins de concessão de benefícios fiscais no âmbito de cada Estado-membro. Talvez referida norma fizesse sentido no momento histórico-político vivido pelo Brasil em período anterior à Constituição Federal de 1988, mas resta de difícil defesa diante dos princípios e valores da contexto democrático atual.

De fato, conforme visto no disposto legal do ADCT, a Lei Complementar $n^{\circ}$ 24/75 foi recepcionada pela Constituição Federal de 1988. No entanto, questiona-se acerca da validade e constitucionalidade do critério de unanimidade (constante do artigo $2^{\circ}$, parágrafo $2^{\circ}$, da Lei Complementar $n^{\circ} 24 / 75$ ) para fins de concessão de benefícios físcais.

Causa estranheza o critério da unanimidade ser sui generis em todo o ordenamento jurídico pátrio. As emendas à Constituição Federal obedecem ao critério de $3 / 5$ dos votos dos representantes em cada casa do Congresso Nacional. Já nos casos de Lei Complementar, é necessária maioria absoluta do Senado Federal e da Câmara dos Deputados. 
Ressalta-se que o papel do CONFAZ é harmonizar as regras tributárias no âmbito do ICMS, mas tem sido um órgão de imposição, sob o argumento de proteção dos Estadosmembros frente à guerra fiscal. Não obstante, os princípios federativos que regem a República, de solidariedade, de lealdade federativa e autonomia dos entes federados encontram dificuldades de concretização em razão da unanimidade estabelecida.

Por meio de uma análise sistêmica do federalismo fiscal brasileiro, torna-se evidente a importância do Senado Federal nessa conjuntura, enquanto representante dos entes federados. Ressalta-se que o Senado Federal tem o poder de editar resolução, de iniciativa do Presidente da República ou de um terço dos Senadores, aprovada pela maioria absoluta de seus membros, estabelecendo as alíquotas aplicáveis às operações e prestações, interestaduais e de exportação relativas ao ICMS.

A proposta em trâmite no Senado Federal (PRS n ${ }^{\circ}$ 1/2013) abrange a uniformização das alíquotas, de forma escalonada até o ano de 2021, no patamar de 4\%. Nas operações com mercadorias e bens produzidos em conformidade com Processo Produtivo Básico nas regiões Norte, Nordeste e Centro-Oeste e no Estado do Espírito Santo, bem como de produtos agropecuários, a alíquota nas operações e prestações interestaduais realizadas nessas três regiões e no Estado do Espírito Santo e destinadas às regiões Sul e Sudeste será reduzida para $7 \%$ a partir de 2018 .

No entanto, a pacificação das alíquotas interestaduais deve vir acompanhada de políticas públicas visando o desenvolvimento do Brasil, sempre de forma atenta às peculiaridades de cada região brasileira. As obrigações assumidas pelos Estados na prestação dos serviços públicos não possuem proporcionalidade em relação às suas receitas. O resultados desse descompasso é sentido de forma evidente na conformação econômica atual brasileira, em que os Estados encontram-se endividados, sem cumprir com suas obrigações contratuais e de folhas de pagamento, prejudicando os serviços públicos e os contribuintes.

Percebe-se, assim, a instalação de insegurança jurídica evidente no Brasil, em clara afronta ao princípio de segurança jurídica, cuja finalidade é proteger os direitos dos contribuintes perante todo o sistema tributário nacional, como decorrência da confiança 
legítima na criação de tributos e na gestão do sistema tributário, gerando estabilidade (tratada por Luhmann).

Niklas Luhmann trata a estabilidade das normas como uma característica importante de um sistema em relação à sociedade complexa. O direito não somente se ajusta aos conflitos, mas também os produz. Na concepção do sistema autopoiético de produção e solução de litígios, o direito é representado como elemento essencial para a concretização do princípio da segurança jurídica e como critério de aferibilidade da certeza do direito.

A confiança legítima tem estreita relação com a pretensão de eficácia da Constituição, visto que tem o objetivo de estabelecer ordem e conformação à realidade política e social. Existe, portanto, nos objetivos da Constituição, uma via de mão dupla, segundo a qual a norma jurídica determina a realidade social e, igualmente, é determinada por ela. Não se pode vislumbrar apenas a realidade social e tampouco somente a normatividade pura.

Como visto, a função do direito como mecanismo de estabilização das expectativas das normas tem papel essencial o regulador de conflitos federativos. O direito não só se ajusta aos conflitos, mas também os produz, como no caso da guerra fiscal. Na concepção de um sistema autopoiético de produção e redução de litígios, participa como fundamental na concretização do princípio da segurança jurídica.

Resta bastante claro, portanto, que a segurança jurídica e suas garantias derivadas, como proibição de excesso, proporcionalidade, razoabilidade, acessibilidade e confiança legítima, são direitos assegurados aos contribuintes, consistindo, ainda de maneira indireta, em limitações constitucionais ao poder de tributar.

No contexto atual existente no Brasil, percebe-se que tem se instaurado um quadro de insegurança jurídica bastante intenso para os contribuintes. Conforme explicitado, na dificuldade de se definir o critério de justiça, utiliza-se o parâmetro da legalidade para segurança dos cidadãos. Referido parâmetro deve ser seguido, sempre em coordenação com os princípios constitucionais estabelecidos. 
No entanto, no caso em comento, tem-se a guerra fiscal, que se perfaz em um problema estrutural na repartição de competências tributárias, nos termos históricos estudados no presente trabalho, corroendo os direitos fundamentais dos contribuintes, especialmente no que se refere à ausência de previsibilidade das relações com o poder público.

A concessão de benefícios por parte dos Estados sem a existência e convênio aprovado de forma unânime no âmbito do CONFAZ, nos termos da exigência legal até hoje vigente (embora já tenhamos demonstrado a inviabilidade federativa de referido requisito, propondo-se a alteração), traz impactos significativos para os contribuintes, isso porque as concessões de benefícios e incentivos fiscais trajam vestes regulares e aparentemente jurídicas, e, portanto, justas.

Contudo, vários problemas foram constatados acerca dessa temática, que vão desde a invasão da autonomia estadual ou municipal até a guerra fiscal, a partir da inobservância das regras legais ou constitucionais. Vê-se, então, que seria viável a edição de uma nova norma geral que desse maior homogeneidade aos critérios de aplicabilidade do ICMS entre os Estados-membros e coibisse a concessão de benefícios fiscais sem a autorização do CONFAZ. O critério para aprovação de benefícios fiscais no âmbito do referido Conselho seria a maioria, seguindo a concepção democrática em que está inserida a Federação.

Referida iniciativa ofereceria maior segurança jurídica aos contribuintes, diminuiria a litigiosidade fiscal e permitiria a redução do custo de conformidade, tão alto e preocupante no Brasil. A preocupação com pacto federativo deve atentar-se para os entes federados, mas, igualmente, para os contribuintes, elo politicamente mais fraco dessa cadeia, embora seja a mola propulsora da economia e, portanto, da arrecadação tributária.

Outra questão relevante sobre o tema é a ausência de transparência fiscal nas relações entre os Estados e os contribuintes, visto que a segurança jurídica apenas pode estar presente onde se possa identificar o conteúdo normativo de forma clara.

Por fim, conclui-se que os contribuintes se encontram em um ambiente de dúvidas sobre a aplicabilidade das normas, validade e constitucionalidade delas, além da relação conturbada entre os Estados da Federação. A existência de legislação em grande 
quantidade, bem como a ausência de compilação das normas cooperam para este cenário, enfraquecendo o pacto federativo.

A reforma fiscal, portanto, é urgente e deve ser realizada de forma ampla, por meio de um compromisso assumido por todos os entes da Federação. Não se pode remediar situações emergenciais sem que haja um plano de desenvolvimento nacional, visando a ampliação das redes de infraestrutura e aumento da eficiência. 


\section{REFERÊNCIAS}

AFONSO, José Roberto. Federalismo e a questão tributária. Rev. Paraná

Desenvolvimento, n. 84, Curitiba, jan/abril 1995, p. 19-26.

AFONSO, José Roberto; RAMUNDO, Júlio César ; ARAÚJO, Erika Amorim . Breves Notas Sobre o Federalismo Fiscal no Brasil. Rio: BNDES, 1998 (Notas Técnicas).

AFFONSO, Rui de Britto Álvares; SILVA, Pedro Luiz Barros (org.). A Federação em perspectivas: ensaios selecionados. São Paulo: FUNDAP, 1995.

ALEOVER, Pilar G. El Derecho en la Teoría de la Sociedade em Niklas Luhmann. Barcelona: JM Bosch, 1993.

ALEXY, Robert. Teoria dos direitos fundamentais. Tradução de Virgílio Afonso da Silva. São Paulo: Malheiros, 2008.

ANDRADE, José Maria Arruda de. Competência Concorrente e a Definição de Normas Gerais. In: Série Pensando o Direito n. 13/2009. Brasília, DF: Ministério da Justiça, 2009.

ANDRADE, Paes; BONAVIDES, Paulo. História constitucional do Brasil. 6. ed. Brasília: OAB editora, 2004.

ANSELMO, José Roberto. O papel do Supremo Tribunal Federal na concretização do federalismo brasileiro. 2006. Tese de Doutorado - Pontifícia Universidade Católica de São Paulo, São Paulo, 2006.

ARRETCHE, Marta. Federalismo e relações intergovernamentais no Brasil: a reforma de programas sociais. Seminário temático "Federalismo, Instituições e Políticas Públicas no Brasil", ANPOCS, 2001.

ATALIBA, Geraldo. Competência legislativa supletiva estadual. RDP 62/26.

BALEEIRO, Aliomar. Limitações constitucionais ao poder de tributar. Rio de Janeiro: Forense, 1997. 
. Direito tributário brasileiro. 11 ed. atualizada por Misabel Abreu Machado Derzi. Rio de Janeiro: Forense, 2010.

BARBOSA, Fernando de Holanda. Federalismo Fiscal, Eficiência e Equidade: Uma Proposta de Reforma Tributária. Brasília: SINAFRESP/FENAFISCO, 1998.

BARROSO, Luis Roberto. Direito Constitucional Brasileiro: o problema da federação. Rio de janeiro: Forense, 1982.

BERCOVICI, Gilberto. Constituição econômica e desenvolvimento: uma leitura a partir da Constituição de 1988. São Paulo: Malheiros, 2005.

2003.

Desigualdades regionais, Estado e Constituição. São Paulo: Max Limonad,

. Federalismo e desenvolvimento regional no Brasil. In: SCHOUERI, Luís

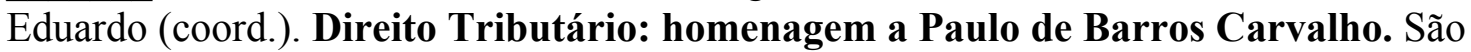
Paulo: Quartier Latin, 2008. P. 889-906.

BONAVIDES, Paulo. Curso de Direito Constitucional. 6. ed. São Paulo: Malheiros, 1996.

Ciência Política. 10. ed. rev. atual. São Paulo: Malheiros, 2000.

BOBBIO, Norberto. Teoria do Ordenamento Jurídico. 5. ed. Brasília: UnB, 1994.

Dicionário de política. 10. ed. Brasília: Ed. UNB, 1997.

BOUVIER, Michel. Les finances locales. 15. ed. Paris: LGDJ, 2013.

BOUVIER, Michel. Introduction au droit fiscal general et à la théorie de l'impôt. 12. ed. Paris: LGDJ, 2014.

BRANTON, William. MCCAHERY, Joseph. Fiscal federalism, tax harmonization and wealth redistribution. Public law and legal theory, working paper 006, jan./2000. 
BRASIL. Código Tributário Nacional. Lei no 5.172, de 25 de Outubro de 1966. Diário Oficial da União, Brasília, DF, 27 out. 1966.

BRASIL. Constituição (1988). Constituição da República Federativa do Brasil. Brasília, DF: Senado, 1988.

BUCHANAN, James M. Federalism and Fiscal Equity. The American Economic Review, v. 40, n. 4, sep. 1950, p. 583-599.

CAGGIANO, Monica Herman. Explorando o Federalismo. Revista Direito Mackenzie, São Paulo: Mackenzie, ano 1, n.2, p. 139-172.

CAGNONE, Miranda Carvalho. O artigo 23 da constituição federal de 1988 e a estrutura do federalismo cooperativo no Brasil. 2008. Dissertação de Mestrado Universidade Presbiteriana Mackenzie, São Paulo, 2008.

CAMPILONGO, Celso Fernandes. O direito na sociedade complexa. São Paulo. Saraiva, 2011.

CANOTILHO, José Joaquim Gomes. Direito Constitucional e Teoria da Constituição. Coimbra: Almedina. 1998.

CANOTILHO, José Joaquim Gomes; MENDES, Gilmar Ferreira; SARLET, Ingo Wolfgang; STRECK, Lenio Luiz (coord.). Comentários à Constituição do Brasil. São Paulo: Saraiva/Almedina, 2013.

CARLUCI, José Lence. Uma introdução ao sistema aduaneiro. São Paulo: Aduaneiras, 1996.

CARRAZZA, Roque Antonio. Curso de direito constitucional tributário: rev e atual. até a emenda constitucional 67/2010. 29. Ed. São Paulo: Malheiros, 2013.

CARVALHO, David Ferreira. Pacto Federativo e Descentralização Fiscal. Papers do NAEA (UFPA), Belém - Pará, v. 138, 2000, p. 1-23.

CARVALHO, Paulo de Barros. Curso de direito tributário. 15. ed. São Paulo: Saraiva, 2003 . 
Direito tributário: linguagem e método. 4. ed. São Paulo: Noeses, 2011.

COELHO, Dulce Maria Alves da Rocha. Federalismo Fiscal no Brasil: uma análise do fundo de participação dos Municípios. 2007. Monografia apresentada no curso de especialização em orçamento público do Tribunal de Contas da União e Câmara dos Deputados. Brasília, 2007.

COELHO, Isaias; SANTI, Eurico (org.). Reforma Tributária Viável: simplificação, transparência e eficiência. São Paulo: Quartier Latin, 2011.

CONTI, José Maurício (org.). Federalismo fiscal. Barueri, SP: Manole, 2004.

. Federalismo fiscal e reforma tributária: utopia ou realidade? In: SCHOUERI, Luís

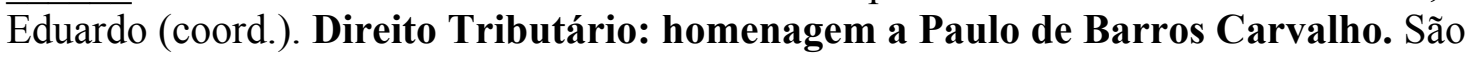
Paulo: Quartier Latin, 2008.

CORBACHO, Ana; CIBILIS, Vicente Fretes; LORA, Eduardo. Recuadar no basta. Los impuestos como instrumento de desarrollo. Washington: BID, 2013.

COURCHENE, Thomas. Federalism and the new economic order: a citizen and process perspective. In: Federalism in the Mercosur: the challenges of regional integration. Porto Alegre, 2000.

DALLARI, Dalmo de Abreu. Elementos da Teoria Geral do Estado. Rio de Janeiro: Saraiva, 1998.

DE GIORGI, Raffaele. Direito, democracia e risco. Vínculos com o futuro. Porto Alegre. Sergio Antonio Fabris Editor, 1998.

EHRLICH, Stanislaw. Theoretical reflexions on federations and federalism. International Political Science Review. Vol. 5, n. 4, 1984, p. 359 a 367.

ELALI, André. O federalismo fiscal brasileiro e o sistema tributário nacional. São Paulo: MP, 2005.

FALCÃO, Maurin Almeida. Desenvolvimento econômico e expansão dos sistemas tributários. Anais do XIII CONPEDI, Florianópolis: 2004. 
FERRAZ JUNIOR, Tércio Sampaio. Introdução ao Estudo do Direito: técnica, decisão, dominação. 4. ed. São Paulo: Atlas, 2003.

FRANÇA, Phillip Gil. Objetivos Fundamentais da República Federativa do Brasil e Escolhas Públicas: Perspectivas de Caminhos Constitucionais de Concretização do Desenvolvimento Intersubjetivo. Revista do Instituto do Direito Brasileiro, v. 2, 2013.

GASSEN, Valcir (org.). Equidade e eficiência da matriz tributária brasileira. 1. ed. Brasília: Consulex, 2012.

GONÇALVES, Guilherme Leite. Função interpretativa, alopoiese do direito e hermenêutica da cordialidade. Revista Direito e Práxis, v. 1, p. 16-31, 2010.

Direito entre certeza e incerteza: horizontes críticos para a teoria dos sistemas. 1. ed. São Paulo: Saraiva, 2013.

GRAU, Eros Roberto. A ordem econômica na Constituição de 1988: interpretação e crítica.

HARADA, Kiyoshi. Direito financeiro e tributário. 15. ed. São Paulo: Atlas, 2006. . HARADA, Kiyoshi. ICMS - operações interestaduais. Uma legislação confusa e insegura. 20/10/2015. www. haradaadvogados.com.br

HESSE, Konrad. A Força Normativa da Constituição. 1. ed. Porto Alegre: Sergio Antonio Fabris Editor, 1991.

HOFMEISTER, Wilhelm e CARNEIRO, José Mário Brasiliense (org.). Federalismo na Alemanha e no Brasil. São Paulo: Konrad-Adenauer-Stiftung, série debates no 22, v. I, abr. 2001.

HORTA, Raul Machado. Direito Constitucional. 4. ed. Belo Horizonte: Del Rey, 2003.

JELLINEK, Georg. Teoria Geral do Estado. México: Fundo de Cultura Econômica, 2002 .

KANT, Immanuel. A Fundamentação da Metafísica dos Costumes. In: A Doutrina Universal do Direito. Tradução Edson Bini. São Paulo: Ícone, 2005. 
KELSEN, Hans. A Democracia. 1a ed., São Paulo: Editora Martins Fontes, 1993.

LAMARQUE, Jean. NÉGRIN, Olivier. AYRAULT, Ludovic. Droit fiscal general. 3. ed. Paris: LexisNexis, 2014.

LEAL, Victor Nunes. Leis federais e leis estaduais. In: Problemas de Direito Público. 1. ed. Rio de Janeiro: Forense, 1960.

LOSANO, Mario. Sistema e estrutura no direito. São Paulo. Vol 3. Martins fontes, 2008.

LOWENBERG, Jacques. Philosophical federalism. The Journal of Philosophy, v. 23, n. 20, set. 1996, p. 533-545.

LUHMANN, Niklas. Legitimação pelo procedimento. Trad. de: Maria da Conceição Corte-Real. Brasília, DF: Editora Universidade de Brasília, 1980.

LUHMANN, Niklas. Sociologia do Direito I. Trad. de: Gustavo Bayer. Rio de Janeiro: Edições Tempo Brasileiro, 1983.

LUHMANN, Niklas. EI derecho de la sociedad. México: Universidade Iberoamericana, 2002.

LUHMANN, Niklas. Law as a social system. Oxford: Oxford University, 2004.

LUHMANN, Niklas. Eı Derecho de la Sociedad. 2. ed. México, D.F.: Universidad Iberoamericana e Heder, 2005.

MACHADO, Hugo de Brito. Curso de direito tributário. 18. ed. São Paulo: Malheiros, 2000.

MARTÍNEZ, Soares. Direito fiscal. 7. ed. Coimbra: Almedina, 1995.

MARTINS, Cláudio. Normas gerais do direito tributário. 2. ed. Rio de Janeiro: Forense, 1969. 
MARTINS, Ives Gandra. Estímulos Fiscais do ICMS e a Unanimidade Exigida no CONFAZ. Revista CEJ, Brasília, Ano XVII, n. 59, p. 22-29, jan./abr. 2013.

MEIRELLES, Hely Lopes. Direito Municipal Brasileiro. 10. ed. São Paulo: Malheiros, 1998.

MENDES, Gilmar Ferreira; COELHO, Inocêncio Mártires; BRANCO, Paulo Gustavo Gonet. Curso de Direito Constitucional. 4. ed. São Paulo: Saraiva, 2009.

MORAES, Alexandre de. Constituição do Brasil Interpretada e legislação constitucional. 6. ed. São Paulo: Atlas, 2006.

MORAES, Marcos Ribeiro de. As Relações Intergovernamentais na República Federal da Alemanha. São Paulo: Fundação Konrad Adenauer, 2001.

NEVES, Marcelo. Entre Têmis e Leviatã: uma relação difícil. Coleção justiça e direito. São Paulo: Martins Fontes, 2012.

OATES, Wallace E. On essay on fiscal federalism. Journal of Economic Literature, vol. 37, n. 3, p. 1120-1149, 1999.

Toward a second-generation theory of fiscal federalism. International Tax and Public Finance, vol. 12, 2005, p. 349-373.

OLIVEIRA, Regis Fernandes de. Curso de direito financeiro. 4. ed. rev. atual. e ampl. São Paulo: Revista dos Tribunais, 2011.

OLIVEIRA, Ricardo Victalino. A configuração assimétrica do federalismo brasileiro. 2010. Dissertação de Mestrado na Universidade de São Paulo. São Paulo, 2010.

PADOIN, Maria M; PASSAMANI, Guilherme R. Um olhar sobre a proposta federalista de Proudhon. Primer Encuentro de ADHILAC - Argentina, Buenos Aires, nov. 2003.

PALMA, Clotilde Celorico. Introdução ao imposto sobre valor acrescentado. Coimbra: Almedina, 2005.

PARSONS, Talcott. The social system. Nova York: Free Press, 1951. 
PAULA Jr., Aldo de. A Guerra Fiscal esta morta. Vida londa à Guerra Fiscal. JOTA, 13 mar. 2015.

PEREIRA, Geailson. O Direito como sistema autopoiético. Revista CEJ, Brasília, Ano XV, n. 55, p. 86-92, out./dez. 2011.

POLIZELLI, Vitor B. Progressividade: distribuição de renda e indução. Direito Tributário Atual, v. 21, 2007, p. 361.

POLITI, R. B.; MATTOS, Enlinson. Competição Vertical e Horizontal no Brasil: uma análise empírica das interações físcais nos mercados de cigarro e de gasolina. Pesquisa e Planejamento Econômico, Rio de Janeiro, v. 42, p. 60-91, 2012.

PRADO, Sérgio. Guerra Fiscal e Políticas de Desenvolvimento Estadual no Brasil. Economia e Sociedade, Campinas, v. 13, p. 1-40, dez. 1999.

Equalização e federalismo fiscal: uma análise comparada. Rio de Janeiro: Konrad-Adenauer-Stiftung, 2006.

PROUDHON, Pierre-Joseph. Do princípio federativo. São Paulo: Nu-Sol: Imaginário, 2001 .

REVERBEL, Carlos Eduardo Dieder. O federalismo numa visão tridimensional do direito. 2008. Dissertação de Mestrado - UFRGS, Porto Algere, 2008.

REZENDE, Fernando; OLIVEIRA, Fabrício Augusto de (Org.). Descentralização e federalismo fiscal no Brasil. Desafios da Reforma Tributária. Rio de Janeiro: Konrad Adenauer Stiftung, 2003.

REZENDE, Fernando (coord.). Globalização, federalismo e tributação. Planejamento e Políticas Públicas, n. 20, IPEA, 1999.

Desafios do federalismo fiscal. Rio de Janeiro: FGV, 2006.

Regionalismo e federalismo fiscal: Novos desafios. IDP/FGV, setembro/2011.

O federalismo brasileiro em seu labirinto. Crise e necessidade de reformas. Rio de Janeiro: FGV, 2013. 
RIANI, Flávio. Economia do setor público. 2. ed. São Paulo: Atlas, 1990.

RODRIGUES, Leo Peixoto; NEVES, Fabrício Monteiro. Niklas Luhmann: a sociedade como sistema. Porto Alegre: Edipucrs, 2012.

RUIPÉREZ, Javier. Entre el federalismo y el confederalismo: dificultades y problemas para la formulación de una teoria constitucional del Estado de las autonomías. Biblioteca Nueva, Madrid: 2010.

SANTIAGO, Igor M. Resolução 13 é cortina de fumaça na guerra dos portos. Conjur, 2013.

SANTOS, Ronaldo Alencar; ANDRADE, Priscila Lopes. A Evolução Histórica do Federalismo Brasileiro: Uma Análise Histórico-Sociológica a partir das Constituições Federais. XXI Encontro Nacional do CONPEDI. 1. ed. Florianópolis: Fundação Boiteux, 2012, v. XXI, p. 8-14794.

SARAIVA FILHO, Oswaldo Othon de Pontes (org.). Reforma tributária. Belo Horizonte: Fórum, 2004.

SCAFF, Fernando Facury. A Inconstitucional unanimidade do CONFAZ e o surpreendente convênio 70. Conjur, 12 ago. 2014.

SCHOUERI, Luís Eduardo. Direito Tributário. 3. ed. São Paulo: Saraiva, 2013.

SERRA, José; AFONSO, José Roberto. Federalismo Fiscal à brasileira: algumas reflexões. Revista do BNDES, Rio de Janeiro, v. 6, n. 12, p. 3-30, dez. 1999.

SILVA, José Afonso da. Comentário contextual à Constituição. 7. ed. São Paulo: Malheiros, 2010.

SILVA, Mauro Santos. Teoria do Federalismo Fiscal: Notas sobre as contribuições de Oates, Musgrave, Shah e Ter-Minassian. Revista Nova Economia, Belo Horizonte, v. 15, p. 117-137, 2005.

SILVEIRA, Matheus Torma da. Competição tributária horizontal no Brasil: Uma abordagem de economia política moderna. 2015. Dissertação de Mestrado - UFRGS, Porto Alegre, 2015. 
SIQUEIRA, Janilson Bezerra. Federalismo, sistema tributário e guerra fiscal. Tese de doutorado - Universidade Federal de Pernambuco, Recife, 2004.

SOUZA, Celina. Federalização de políticas públicas no Brasil: papel das regras e do contexto. Studia Politicae, Córdoba, n. 17, p. 11-17, 2009.

TANZI, Vito. Fiscal Federalism and Decentralization: a Review of Some Efficiency and Macroeconomic Aspects. Annual Bank Conference on Development Economics World Bank, Washington, D.C., 1995.

TEIXEIRA, Alessandra Machado Brandão. A Tributação Sobre o Consumo de Bens e Serviços. Belo Horizonte: Mandamentos, 2002.

TER-MINASSIAN, Teresa. Fiscal Federalism in Theory and Practice. Washington: Internacional Monetary Fund, 1997.

TEUBNER, Gunther. Direito, sistema e policontexturalidade. Tradução de Brunela Vieira de Vicenzi et al. Piracicaba: Editora Unimep, 2005.

. Fragmentos Constitucionais. Constitucionalismo social na globalização. 1a ed. São Paulo: Saraiva, 2016.

TORRES, Heleno Taveira. Direito Constitucional Tributário e Segurança Jurídica. 2. ed. São Paulo: RT, 2012.

. Teoria da Constituição Financeira. Tese apresentada ao Concurso de Professor Titular de Direito Financeiro da Faculdade de Direito da Universidade de São Paulo. São Paulo, 2014.

Reformas do federalismo fiscal avançam no Brasil. Conjur, 2015.

TORRES, Ricardo Lobo. Curso de direito financeiro e tributário. 9. ed. Rio de Janeiro: Renovar, 2002.

. É possível a criação do IVA no Brasil? Revista Fórum de Direito Tributário -

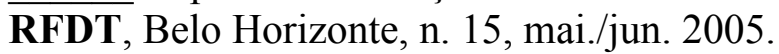


TRATADO DA UNIÃO EUROPÉIA. Maastricht, 1992.

TREVES, Renato. Sociologia do Direito. São Paulo: Manole, 2004.

VILLAS BOAS, Orlando; GONÇALVES, Guilherme Leite. Teoria dos sistemas sociais. Direito e sociedade na obra de Niklas Luhmann. São Paulo: Saraiva, 2013.

ZILVETTI, Fernando Aurelio. Princípios de Direito Tributário e a Capacidade Contributiva. São Paulo: Quartier Latin, 2004.

ZIMMERMANN, Augusto. Teoria Geral do Federalismo Democrático. 2. ed. Rio de Janeiro: Lumen Juris, 2005. 